\title{
Managing farming systems, landscapes, pests and pathogens to improve consumer perception of berries
}

\author{
Marvin Pritts \\ Department of Horticulture, Cornell University, Ithaca, NY, USA \\ E-mail:mpp3@cornell.edu
}

Received 20 June 2011; accepted 29 July 2011

\begin{abstract}
A major challenge in berry production is the management of pests. Traditionally, growers have used pesticides to manage weeds, arthropods and pathogens, but pressure has been increasing to reduce or eliminate their use. A multitude of approaches and technologies exist that could potentially reduce pesticide use and increase consumer acceptance of berries. Many of these have not yet been widely used in the production of berries. The intent of this paper is to identify ten promising approaches that can lead to reduced pesticide use, and provide examples of how these can be applied to berry production in the future.
\end{abstract}

Keywords: Breeding, Fragaria, genetic engineering, insect, organic, pesticide, Ribes, Rubus, Vaccinium, virus

\section{Introduction}

A major frustration for growers is to produce an abundant crop, only to have it partially or totally destroyed by pests. Losing crops to pests wastes water, energy, nutrients, time and money, and can be a significant contributor to unsustainable production. Managing pests is one of the major tasks involved with growing berries, occasionally involving $70 \%$ of total growing expenses [17]. Berry crops are susceptible to a wide variety of arthropods, pathogens and weeds, and considerable effort has gone into studying ways to control these pests. However, when crop values per hectare are high and total planted area is low, private companies are reluctant to assume the risk associated with developing pest control products for such crops. As a result, berry growers have available to them far fewer pest management products than growers of major agronomic crops. Furthermore, birds and mollusks can significantly damage berry crops, and there is little effort directed at managing these pests because they are outside the traditional pest management subjects of weeds, insects and pathogens. Each of these factors contributes to the significance of pests in the production of berries.

Traditionally, the approach to pest management has been to kill the offending organism. Most growers, even organic growers, use various herbicides, insecticides and fungicides to eliminate the cause of the problem. Because these organisms share much of the same biochemistry with humans and benign organisms, chemicals directed at disrupting a pest's biochemical functions in order to kill them, also may impact human functioning or that of organisms in the environment. Over the last few decades, pesticides have become more specific in an attempt to minimize off-site and human impacts. Typical herbicide application rates have fallen in the last century from 3,000 grams per hectare to 100 , from $2,500 \mathrm{~g} / \mathrm{ha}$ of insecticide to 20 , and from $1,200 \mathrm{~g} / \mathrm{ha}$ of fungicide to 100 [25]. This has resulted in less contamination and persistence. However, pests that were once controlled by broad-spectrum products are now resurging in certain locations, and targeted pests are developing resistance. Despite huge increases in pesticide use 
over time ( $>30$ billion annually) [18], loss of crops to pests (about $30 \%$ on average) has remained substantially unchanged over the last 60 years [13]. This is due, in part, to increasing monocultures, less crop rotation, pest resistance, growing crops in suboptimal climatic regions, introduction of exotic pests, and the use of pesticides that make plants more vulnerable to other pests [25]. Despite the reduction in total pesticide use and more specificity in pesticides, consumers are increasingly concerned about residues in the food supply, however minute the levels [5]. Berries often are targeted and labeled as unsafe by these surveys.

Productivity of plant systems worldwide is also challenged by the international trade in plants and their products. Large volumes of products are transported across oceans and continents every day, and along with them, potential pests that currently do not exist at the destination. With the rapid transportation systems that exist today, items can be shipped in less time than the incubation period of many pathogens, rendering visual inspections useless. It is impractical and not environmentally sound to fumigate all produce being imported into a country as a preventative measure.

Approaches to managing pests are needed that do not rely exclusively on killing the offending organism with a chemical. The following are promising opportunities for managing pests in berry crops that also minimize environmental impact and improve food safety. Development and promotion of these tactics could lead to better consumer acceptance of berry products because the use of pesticides would be reduced.

\section{Opportunities}

\#10) New chemistries and modes of action need to be identified in order to stay ahead of pests. Even though there are more than 1,200 active ingredients used for pest management, many of their modes of action are similar. New chemistries are being introduced to the industry, but because of their specificity, the development of resistance is of greater concern than with older broad-spectrum products. Never-the-less, some targeted killing of pests will be needed well into the future, and it is best if these do not impact beneficial and non-target species, and are effective at low rates. But regardless of how effective they are, it will be a never-ending race to stay ahead of pests that can evolve resistance to most manufactured chemicals. Glyphosate is an example of a product that provided a new mode of action, is inexpensive, and has been considered relatively environmentally benign. But resistance has now occurred in several weed species after heavy use [23], and this evolution will eventually lead to the need for newer broad-spectrum chemistry with equal or less environmental impact.

\#9) Better understanding of pest biology and thresholds. Thresholds need to be developed and refined through collaborations with economists. Despite years of research, few thresholds exist for berry pests. There is a clear need to develop such thresholds so that appropriate management decisions can be made. Considerable opportunities exist to develop technologies to aid in scouting, such as pheromones, vacuums, baits, or other technologies. Similarly, little work exists on the use of weather data to predict activity of pests. Berry crops lag behind agronomic crops, grapes (Vitis) and apples (Malus) in this regard. Berry growers are too often in the position where they have to react to an infestation, rather than take preventative action before a pest invades or exceeds a threshold.

A better understanding of pest biology will allow for better risk assessments. Currently, implementation of some technologies (e.g. transgenic insects) is delayed because of lack of basic knowledge about pest life cycles, distributions and behaviors.

\#8) Breeding for resistance. Crops that are resistant to pests would seem to be the ultimate solution to pest management. However, breeding for resistance to pests in berry crops is challenging for many reasons. Often sources of resistance have not been identified. Even when they have been identified, multiple races of pathogen may exist, and resistance to each may not exist in a single gene (e.g. Phytophthora fragariae). Even when a source of resistance is found, the complex genetics of berries (polyploidy coupled with inbreeding depression) makes incorporation of such genes difficult at worst, and slow at best. In cases where resistance genes have been identified and incorporated into the crop (e.g. large raspberry aphid resistance), evolution will eventually prevail and the resistance breaks down [1]. Furthermore, breeding programs are expensive to maintain. For example, half of CGIAR's (Consultative Group on International Agricultural Research) $\$ 300,000,000$ budget is now involved in maintenance breeding, rather than being directed at increasing yield [25]. Breeding programs, at least at publicly-funded institutions, are being abandoned because of expense. 
Genetic engineering holds promise to speed the introduction of resistance genes into berry plants. However, most transgenic crops have been developed for herbicide resistance rather than pest resistance, leading to skepticism among consumers regarding the motivation behind the technology as such uses do not improve food quality. Another common use of this technology is incorporating insect toxins into plants (e.g. Bacillus thuringiensis toxin production), but consuming toxins of any kind makes consumers nervous. However, tremendous potential exists for engineering virus resistance into berry crops as this is relatively easy technology with fewer proprietary hurdles. Papayas (Carica papaya), for example, have had engineered virus resistance for decades. Recently, plants have been engineered to produce aphid alarm pheromone. Normally, aphids react to the pheromone by leaving the area or dropping off the plant. But once habituated to a simple compound like beta-farnesene, aphids no longer react, making them very vulnerable to predators [4]. Genetically down-regulating the senescence process through genetic engineering could result in larger fruit (since cells would keep dividing) with increased sugars (since leaves would photosynthesize longer) and perhaps less vulnerability to pests. Although acceptance of this technology for fresh fruit production is still low based on lingering biosafety concerns [7], there may be creative approaches of using genetic engineering to manage pests that are more acceptable.

\#7) Disruption without toxins. Although most chemicals have been developed to kill pests, advances will continue to be made using chemicals to disrupt feeding, mating and reproduction that have little to no impact on the environment. Sucrose sprays and methyl anthranilate (a natural flavor found in 'Concord' grapes), for example, have been shown to deter feeding of birds on blueberries (Vaccinium corymbosum) [2, 22]. 'Surround' kaolin clay sprays deter insect feeding on leaves. Mating disruption pheromones have been used to reduce egg-laying in fruits. Some insects use chemicals to indicate when eggs have been laid in fruits to discourage other insects from laying in that same fruit. If such compounds could be synthesized, then growers could falsely signal to insects that all the fruits in a planting have received eggs, so they would look elsewhere. There are likely thousands of compounds that disrupt the behavior and social interactions of arthropod pests.

Simple compounds also can disrupt the reproduction of fungi. Sulfur and potassium bicarbonate are classic examples of chemicals that prevent reproduction in powdery mildew. Calcium sulfate has been shown to suppress Phytophthora root rot in raspberries (Rubus idaeus) [11]. There are undoubtedly many other compounds that inhibit the life cycles of pests without substantial environmental impacts.

\#6) Introduction and/or conservation of beneficial organisms. The benefits of introducing or conserving certain organisms into crop ecosystems have been known for many years. Initially, organisms such as Bacillus, Beauveria, Steinernema and baculoviruses were used to displace toxic chemicals and directly kill pests. Predatory mites are now commonly used to control phytophagous mites, either through introduction or judicious selection of insecticides for conservation. Endophytic grasses have been used for years to prevent infestations in plant roots. However, there are many yet undiscovered uses for biologicals in pest management. For example, the number of parasitic wasp species in the world $(>100,000)$ exceeds the number of all fish, birds, mammals, amphibians, reptile species combined [8]. Surely there are parasitoids for some of the insects that impact berry crops. For introduced pests, like the spotted winged drosophila (Drosophila suzukii), biologicals may hold more promise than insecticides if they can track the movement of the pest. In addition, biologicals are also being discovered that enhance a plant's tolerance to stress and to pests, including those that induce systemic acquired resistance [21]. However, the efficacy of biologicals is not as consistent as the chemicals they replace. Environmental conditions play a bigger role in how they work and how they are sustained, which is why they are more widely used in greenhouses than in the field. Understanding how to mitigate the impacts of environment ( $\mathrm{pH}$, moisture, temperature, sunlight) on biological controls can result in important advances.

Using biologicals requires greater knowledge of systems on the part of farmers. Despite their potential, only about $30 \%$ of the biological control programs against alien insects and $60 \%$ against alien weeds have been effective worldwide. Biological control makes up less than $0.5 \%$ of the pest control market. Yet the potential is huge.

\#5) Manage the entire landscape, not just the berry planting. Most efforts in the past have been directed at managing the pest in the grower's field, with little regard for managing the landscape around the plantings. If recommendations were made to manage the landscape, it was usually to eliminate related host plants that might be reservoirs of bacteria, fungi, viruses or insects. However, mowing surrounding fields during the flowering of strawberries (Fragaria $\times$ ananassa) or raspberries (Rubus idaeus) can send Lygus bugs into the berries and severely damage flowers and fruit. 
Might it be possible to intentionally plant species around berry fields that are particularly attractive to Lygus bugs, drawing them out of berries where they can stay until flowering is complete or killed without directly treating the berries?

We have been experimenting with using canola (Brassica napus) for this purpose. We have found that canola flowers are very attractive to tarnished plant bug - even more so than strawberry flowers. By surrounding strawberry fields with varieties of canola that flower simultaneously with strawberry, we have found that TPB will move from berries to the canola. Our current work is directed at determining how much canola, relative to strawberry, is required, how far should the canola be planted from the berries, and in what configuration should it be planted.

It is well known that birds prefer roosting sites near fruiting fields. They will take shelter in nearby trees and periodically swoop into fields to feed. By removing nearby trees from berry fields, depredation can be reduced considerably. Other pests undoubtedly have preferred overwintering sites that are likely near berry fields, but which have not yet been discovered. Significant advances in pest management would likely be achieved if components of the landscape that support pests could be identified, and then eliminated or used to attract pests out of fields.

\#4) Improve soil health. A fundamental principle of organic and biodynamic farming is to maintain the health of the soil. Conventional farmers typically have viewed the soil mostly as a reservoir for nutrients, or as the host for soil pathogens. However, an increasing body of literature is suggesting that factors other than nutrients and pathogens have an impact on plant growth. Most farmers are now in agreement that maintaining overall soil health is critical for sustained productivity. The presence of certain organisms can suppress plant pathogens, enhance nutrient availability, improve soil physical properties, increase pools of organic matter and improve plant resistance to stress. However, our understanding of these organisms and their roles is very limited. In fact, it is difficult to even survey soil for the presence of certain general types of organisms using current technology. Mostly soil ecologists extract RNA and determine classifications based on molecular relatedness, rather than indentify the organism's taxonomic group. Currently, soil scientists are identifying ways to measure soil health (e.g. a suite of tests involving soil respiration, soil compaction, aggregate stability, available/active carbon, etc) [9]. Advances are soon to come in ways to enhance soil health and provide beneficial organisms with the appropriate kinds of organic matter to sustain them.

The type and quantity of microbes in the soil can determine the effectiveness of herbicides. In some cases, microbes rapidly break down herbicides so their presence requires higher rates to be effective. In other cases, the presence of certain microbes enhances the activity of herbicides. Understanding these relationships in the soil can improve the efficacy of herbicide applications.

\#3) Clean nursery stock. Nurseries have done a good job of eliminating many types of pathogens from nursery stock. Virus indexing has reduced the incidence of infected plants in the trade, and visual inspections have reduced the incidence of red stele and other root rotting pathogens. Micropropagation allows specific cultivars to be propagated in clean environments which does not expose them to pathogens that would otherwise be encountered in the field [6]. However, once clean plants are introduced into the field, some newer pathogens and arthropods are passing through certain screenings and becoming problems when environmental conditions are favorable, resulting in large amounts of pesticides being sprayed in the field. Good molecular diagnostic protocols for screening at the nursery level are needed before infected plants are unintentionally sent to growers. Anthracnose (Colletotrichum sp.) is a serious problem on strawberries because it can multiply rapidly and spread quickly through a planting since nursery stock may be asymptomatic. Angular leaf spot (Xanthomonas fragariae) is another example of a problematic pathogen that can be spread though distribution of nursery stock. Blueberry shock and blueberry scorch viruses have been unintentionally transmitted by nurseries and have put entire regional industries at risk. Plum pox virus in peaches (Prunus persica) and other stone fruit in North America is a recent demonstration of the serious impact infected nursery stock can have on an industry. Cyclamen/tarsonemid mite (Phytonemus pallidus) is an examples of an arthropod that is very difficult to detect, but nursery stock is the primary way it is distributed. Several viruses, when causing single infections in plants, do not cause symptoms, but when multiple infections occur, disease results. Methods to detect these pests at very low levels would be very useful to plant nurseries and the industry.

\#2) Alternatives to fumigation and plastics. Fumigation has been used for years to eliminate pathogens, nematodes, and weed seeds from soil prior to planting. In addition to the effect of eliminating the pest, there is a beneficial effect of methyl bromide on vigor - in particular - that exceeds what can be accounted for by eliminating pests alone. Now 
that methyl bromide is being phased out, alternatives have been sought to replace it [3, 19, 26]. Methyl iodine works well and is less of an ozone depleter, but has environmental problems of its own. Battles are currently being waged in California over its use [10]. However, if land and/or time are available to a grower, crop rotation can provide many of the beneficial effects of fumigation and impact the soil community [12, 14]. Mustards (Brassica sp.), sorghums (Sorghum sp.), marigolds (Tagetes sp.) and others are known to suppress nematodes and weeds when grown as a cover crop prior to planting berries [20]. Others have been identified as non-hosts for nematodes when grown between rows [24]. Although some consumers are loathe to consume berries that have been genetically modified and transformed, it may be possible (and acceptable to consumers) to create super-suppressive cover crops via. genetic engineering and use them in a crop rotation with berries. Creating such cover crops and/or concentrating the active ingredients involved in suppression could mitigate many of the concerns over chemical fumigants.

Cover crops also can substitute for plastic as a weed suppressant. Huge quantities of plastic are used in strawberry growing - enough each year to circle the Earth 13 times with a meter wide strip. Although some plastic is critical for modifying soil temperatures, much is also used primarily for weed suppression. Substituting killed cover crops for plastic mulch can help mitigate environmental impacts of plastic use and disposal [16]. Currently, substitution of cover crops for plastic is limited because of the availability of equipment that is required to plant through killed sods. However, such equipment now exists and is working well for strawberries, raspberries and other berry crops.

\#1) Perhaps the greatest opportunity for improving pest management while reducing pesticide use is improving spray application technology. Much of the pesticide that is applied does not reach the target species [15]. This can lead to drift, off-site impacts, and the inefficient use of product. Shielded sprayers, electrostatic sprayers, air deflectors, more uniform spray droplets, etc. can be engineered into new machines. In addition, new technology that can assess shape and color ought to be harnessed to enable targeted applications to leaves, fruit or pests, rather than to the entire planting and the spaces between plants. Machines that can assess pest infestations and apply pesticides only where needed (e.g. patches of perennial grasses, clusters of berries) could greatly reduce the amount of pesticide required while providing improved coverage and control.

\section{Threats}

Although there are many opportunities for improving pest management efficacy while reducing environmental impacts, threats continue to exist that are beyond our control.

\#1) Low cost, generic, broad spectrum, higher toxicity pesticides will continue to have strong appeal for small and medium-sized farms in countries that have more recently become engaged in contributing to the world's food supply - like vast areas of Asia, Africa and Latin America where intensification of agriculture is just beginning. For these opportunities to be realized, governments will likely have to play a role to reduce the incentives for using cheap, highly toxic pesticides and encourage the adoption of alternative techniques.

\#2) Support is needed for the development of pest management tools for minor crops. Currently, most of the support is directed at major agronomic crops, with little concerted effort directed at minor crops - even though their market value now rivals that of the agronomic crops. As overall support levels diminish, it may be the minor crops that receive proportionally less support.

\#3) Governments should foster innovation and speed up the approval process for new, safer products that are likely to have minimal environmental impacts. Such processes should not disadvantage smaller companies, particularly since smaller companies are more likely to develop products for minor crops.

\#4) There is an emerging crisis regarding who will do research, scouting and pest identification in the future. In most places, human resources are diminishing and the expertise is aging. It is only in areas where concentrated plantings exist that private scouts can earn a living, leaving many growers without access to expertise even if they could afford it. Professional positions (e.g. university faculty and staff, government scientists) are often not being replaced when experts retire. Just as the world is beginning to consume more fruits and vegetables, research support is diminishing.

\#5) Climate change is affecting food production worldwide. Although much thought has been given to the impact of higher carbon dioxide levels and warmer temperatures on crop growth and development, the impact on 
pests has received less consideration. Regions will likely see new pests with the changing climate. In addition, weeds could likely respond more to warmer temperatures and higher carbon dioxide than crops, forcing greater rates of herbicide use.

Despite many challenges, our work can make a huge positive impact on berry producers, the people who eat our product, the perception of berries, and the environment in which we live. Most of us in the audience are employed for the purpose of helping growers and consumers of horticultural crops. All of us have a significant role to play as we discover new approaches to pest management and share these discoveries with students, growers and policymakers.

\section{References}

[1] A.N.E. Birch, A.T. Jones, B. Fenton, G. Malloch, I. Geoghegan, S.C. Gordon, J. Hillier and G. Begg, Resistance-breaking raspberry aphid biotypes: Constraints to sustainable control through plant breeding, Acta Hort 585 (2002), 315-317.

[2] P. Curtis, I. Merwin and M. Pritts, Chemical repellents reduce bird depredation in fruit plantings, Hort Sci 29 (1994), 1151-1155.

[3] F. D'Anna, G. Fici, G. Angileri, G. Signorino, V. Mezzapelle, F. Amato, A. Moncada, G. Caracciolo, M.L. Palermo and C. Prinzivalli, Alternatives to methyl bromide in strawberry cultivation, Acta Hort 2 (2009), 745.

[4] M. De Vos, W.Y. Cheng, H.E. Summers, R.A. Raguso and G. Jander, Alarm pheromone habituation in Myzus persicae has fitness consequences and causes extensive gene expression changes, Proc Natl Acad Sci 107 (2010), 14673-14678.

[5] Environmental Working Group, Shopper's guide to pesticides. Washington, D.C, 2010.

[6] S.D. Hamill, M.K. Smith and J.A. Moisander, Micropropagation of vegetatively propagated crops: accelerating release of new cultivars and providing an important source of clean planting material, Acta Hort 829 (2009), 213-218.

[7] A.G. Haslberger, Need for an "integrated safety assessment" of GMOs, linking food safety and environmental considerations, J Agric Food Chem 54 (2006), 3173.

[8] H.V. Howell, J.T. Daly and A.H. Doyen, Introduction to insect biology and diversity, Oxford Press, New York, 1998.

[9] O.J. Idowu, H.M. van Es, G.S. Abawi, D.W. Wolfe, R.R. Schindelbeck, B.N. Moebius-Clune and B.K. Gugino, Use of an integrative soil health test for evaluation of soil management impacts, Renewable Agriculture and Food Systems 24 (2009), $214-224$.

[10] G. Ludwig, Methyl iodide controversy continues, Western Farm Press, Penton Media, Inc., New York, 2010.

[11] K. Maloney, M. Pritts, W. Wilcox and M.J. Kelly, Suppression of Phytophthora root rot in red raspberries with cultural practices and soil amendments, HortSci 40 (2005), 1790-1795.

[12] M.J. Mochizuki, H.M. Van Es, T. Bjorkman, A. Rangarajan and R.R. Bellinder, Rye mulch management affects short-term indicators of soil quality in the transition to conservation tillage for cabbage, Hort Sci 43 (2008), 862-867.

[13] E.C. Oerke, H.W. Dehne, F. Schohnbeck and A. Weber, Crop production and crop protection: Estimated losses in major food and cash crops, Eslevier, Amsterdam, 1995.

[14] R.E. Peachey, A. Moldenke, R.D. William, R. Berry, E. Ingham and E. Groth, Effect of cover crops and tillage system on symphylan (Symphlya: Scutigerella immaculata, Newport) and Pergamasus quisquiliarum Canestrini (Acari: Mesostigmata) populations, and other soil organisms in agricultural soils, Applied Soil Ecology 21 (2002), 59-70.

[15] D. Pimentel and L. Levitan, Pesticide amounts and amounts reaching pests, BioSci 36 (1986), 86-91.

[16] M.P. Pritts and M.J. Kelly, Alternative weed control strategies for strawberries, Acta Hort 348 (1993), $321-327$.

[17] M. Pritts and D. Handley, Strawberry production guide. Northeast Resource, Agri and Engineering Service - (1998), 88.

[18] S.K. Ritter, Pinpointing trends in pesticide use, Chemical and Engineering News (2009), 87(7). http://pubs.acs.org/cen/coverstory/87/ 8707cover1a.html

[19] J.B. Samtani, S. Klose, J. Hunzie, S.A. Fennimore, H.A. Ajwa, J.B. Weber and G.T. Browne, Evaluation of non-fumigant alternatives to methyl bromide for weed control and crop yield in California strawberries (Fragaria ananassa L.), Crop Protection 30 (2011), 45

[20] A.T. Seigies, M.P. Pritts and M.J. Kelly, Cover crop rotations alter soil microbiology and reduce replant disorders in strawberry, Hort Sci 41 (2006), 1303-1308.

[21] M. Shoresh, F. Mastouri and G.E. Harman, Induced systemic resistance and plant responses to fungal biocontrol agents, Annu Rev Phytopathol 48 (2010), Published on line.

[22] A.M. Socci, M.P. Pritts and M.J. Kelly, Potential use of sucrose as a feeding deterrent for frugivorous birds, Hort Technol 7 (1997), $250-252$.

[23] M.M. Vila-Aiub, R. Vidal, M. Balbi, P. Gundel, F. Trucco and C. Ghersa, Glyphosate-resistant weeds of South American cropping systems: An overview, Pest Mgt Sci 4 (2008), 366-371.

[24] T. Vrain, S. Freyman, J. Hall and R. Deyoung, Cover crops resistant to root-lesion nematodes in raspberry, Hort Sci 31 (1996), $1195-1198$.

[25] M. Yudelman, A. Ratta and D. Nygaard, Pest management and food production, In: Food, Agriculture and Environment, Intl Food Policy Res Inst, Washington, DC, USA, 1998.

[26] I. Zasada, M. Patrika, T. Walters and J.N. Pinkerton, Methyl bromide alternatives trials in raspberry nurseries, Proc Ann Intern Res Conf on Methyl Bromide Alternatives and Emissions Reductions, 2010. 